Part of Journal of Research of the National Bureau of Standards, Volume 27, August 1941

\title{
THERMAL EXPANSION OF CAST AND OF SWAGED CHROMIUM
}

\author{
By Peter Hidnert
}

ABSTRACT

Data were obtained on the linear thermal expansion of six samples of chromium (99.2 to 96.3 percent) at various temperatures between $-190^{\circ}$ and $+707^{\circ} \mathrm{C}$. The expansion curves indicated anomalies at low temperatures. These anomalies were reversible on heating and cooling. The temperature at which anomalous expansion occurs appears to decrease with decrease in the purity of the chromium. Hysteresis was not observed on heating cast or swaged chromium to $300^{\circ} \mathrm{C}$ and cooling to low temperatures. Exceptionally low average coefficients of expansion were found for temperature ranges in or near the anomalous regions. The average coefficients of expansion of the samples of chromium from $20^{\circ} \mathrm{C}$ to various temperatures between $100^{\circ}$ and $700^{\circ} \mathrm{C}$ lie between $5.7 \times 10^{-6}$ and $10.3 \times 10^{-6}$ per degree centigrade.

\section{CONTENTS}

I. Introduction _._ Page

II. Materials investigated

III. Apparatus

IV. Results

V. Discussion

VI. References

\section{INTRODUCTION}

In a recent publication, the author [1] ${ }^{1}$ reported data on the linear thermal expansion of electrolytic chromium at various temperatures between $-105^{\circ}$ and $+715^{\circ} \mathrm{C}$. Electrolytic chromium was found to contract during the first heating, when hydrogen presumably was evolved. It was possible to obtain smooth expansion curves after repeated heating.

The present paper gives results of an investigation on the linear thermal expansion of cast and of hot-swaged chromium at various temperatures between $-190^{\circ}$ and $+707^{\circ} \mathrm{C}$.

\section{MATERIALS INVESTIGATED}

Table 1 gives the chemical composition and the density of the samples of chromium which were investigated. Sample 1343I was prepared by Westinghouse Electric \& Mfg. Co., Pittsburgh, Pa.; samples 1284, 1356, and 1356I by Research Department, Westinghouse Lamp Division, Bloomfield, N. J.; sample 1443I by P. Hidnert and F. R. Caldwell of the National Bureau of Standards; and sample 1285 was prepared by the Union Carbide \& Carbon Research Laboratories, Inc., New York, N. Y.

\footnotetext{
1 Figures in brackets indicate the references at the end of this paper.
} 
TABLE 1.-Chemical composition and density of chromium

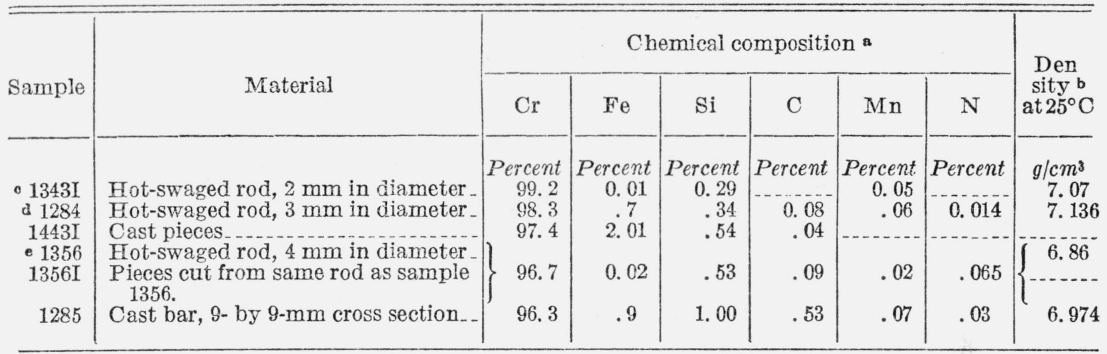

a Determined by R. M. Fowler, C. P. Larrabee, and J. C. Redmond, formerly of the National Bureau of Standards. Possibly the major amount of the undetermined percentage is oxygen. Some of the low-carbon samples may contain aluminum.

b Determined by E. Hill and S. Alpher, formerly of the National Bureau of Standards. Density determination on sample 1343I was made before the expansion tests. Other density determinations were made after the expansion tests.

- Found to be magnetic by H. L. Curtis of the National Bureau of Standards.

d Nickel, not detected. Duplicate sample was found to be diamagnetic by H. L. Curtis of the National Bureau of Standards.

oxygen, 1.05 percent; hydrogen, not detected. The values for oxygen and nitrogen are probably low on account of the presence of some oxide which was not decomposed by vacuum fusion.

\section{APPARATUS}

Samples 1343I, 1443I, and $1356 \mathrm{I}$ were investigated at various temperatures between $-118^{\circ}$ and $+707^{\circ} \mathrm{C}$ with the interferometer method $^{2}$ [2] of measuring thermal expansion. Each sample consisted of three pieces of chromium of nearly equal length. The lengths of samples 1343I, 1443I, and 1356I were $6.648,8.380$, and $7.470 \mathrm{~mm}$, respectively. The temperatures between room temperature and $-118^{\circ} \mathrm{C}$ were obtained by passing liquid air through a coil in the furnace.

The precision comparator type of thermal-expansion apparatus described by Souder and Hidnert [4] was used at various temperatures between $-127^{\circ}$ and $+701^{\circ} \mathrm{C}$ for six tests on sample 1284 and six tests on sample 1285. Tests 1 to 4 of each sample were made with the oil bath shown at the extreme right of figure 1 of their publication. Figure 3 of the same publication shows a sample, sample holder, and contact fingers for the vertical observation wires used in the oil bath. Tests 5 and 6 of each sample were made with the white furnace shown at the left of figure 1 of the publication by Souder and Hidnert [4]. Figure 4 of their publication indicates the method used in mounting each sample in the furnace. The lengths of samples 1284 and 1285 were 298 and $300 \mathrm{~mm}$, respectively.

The fused-quartz thermal-expansion apparatus described by Hidnert and Sweeney [5] was used for sample 1356 and for tests 7 and 8 of sample 1284. The length of sample $1356 \mathrm{was} 170 \mathrm{~mm}$. Sample 1284 was cut to a 201-mm length before use in this apparatus.

At each observation in each type of apparatus, the temperature was kept constant for a sufficiently long time to make certain that the sample had attained constant temperature.

3 The agreement between the results obtained with the interferometer method and the precision comparator method indicates that tilting of the specimens in the interferometer, which has been investigated by Saunders [3], was not an appreciable source of error in the measurements reported here. Numerotis other examples in the literature, which show godd doreement betwean the interferometer method and other methods, also indicate that most of the measurements made by the interferometer method have been freo from serious errors. 


\section{RESULTS}

Figures 1 to 6 , inclusive, show the observations ${ }^{3}$ obtained on the linear thermal expansion of the six samples of chromium. Each expansion curve was plotted from a different origin. The dotted

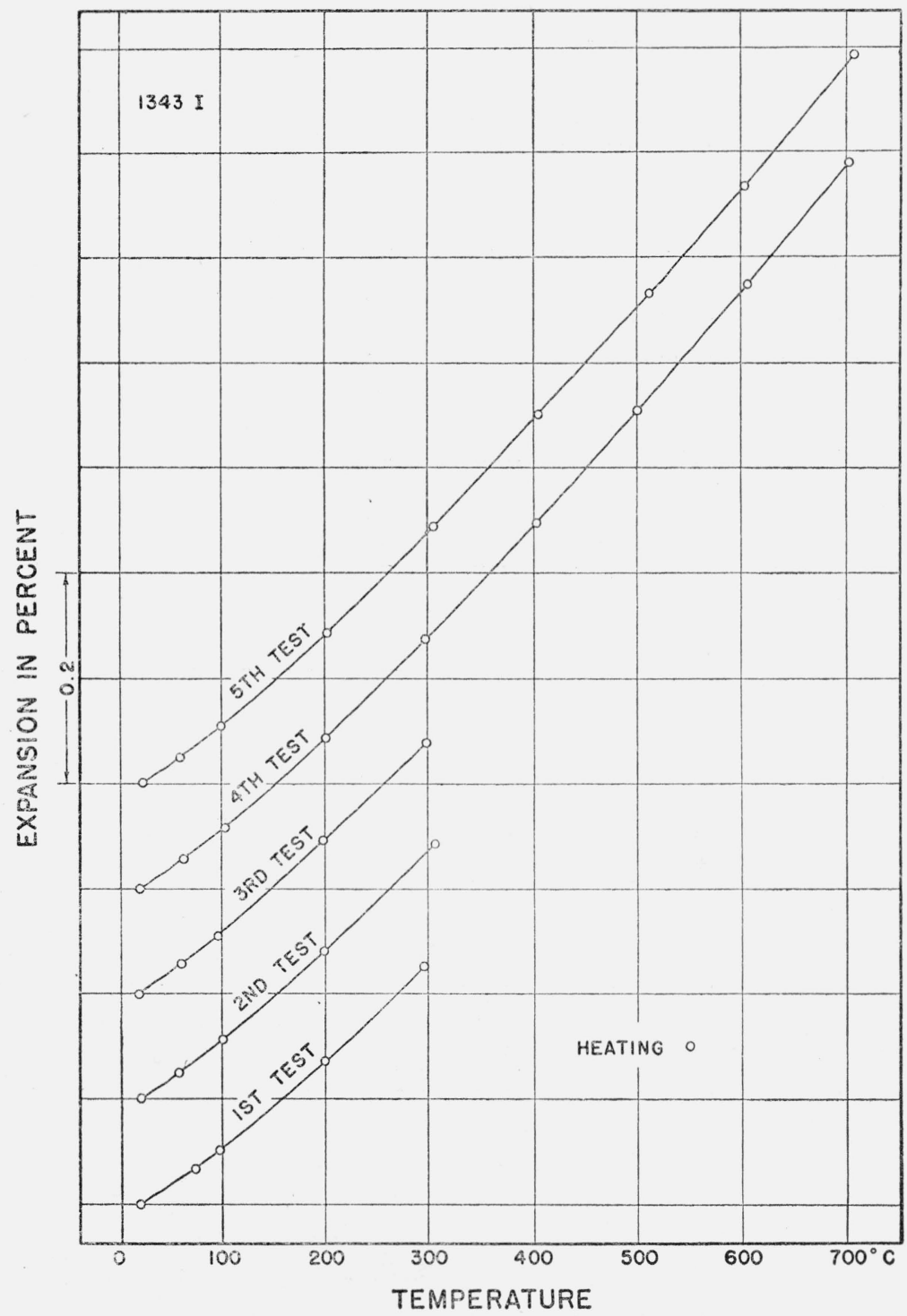

FiguRe 1.-Linear thermal expansion of hot-swaged chromium, 99.2 percent.

portions of two curves indicate that in these regions sufficient observations were not obtained to locate the curves definitely. All expansion curves in figures 1 to 6 , inclusive, are convex toward the temperature axis, except those which will be indicated later.

${ }^{3}$ Some of the observations were omitted in order to avoid confusion. They were too closely spaced to be reproduced on figures of this size. 
The observations obtained in five tests on heating the hot-swaged 99.2-percent chromium (sample 1343 I) to various temperatures between room temperature and $707^{\circ} \mathrm{C}$ are shown in figure 1.

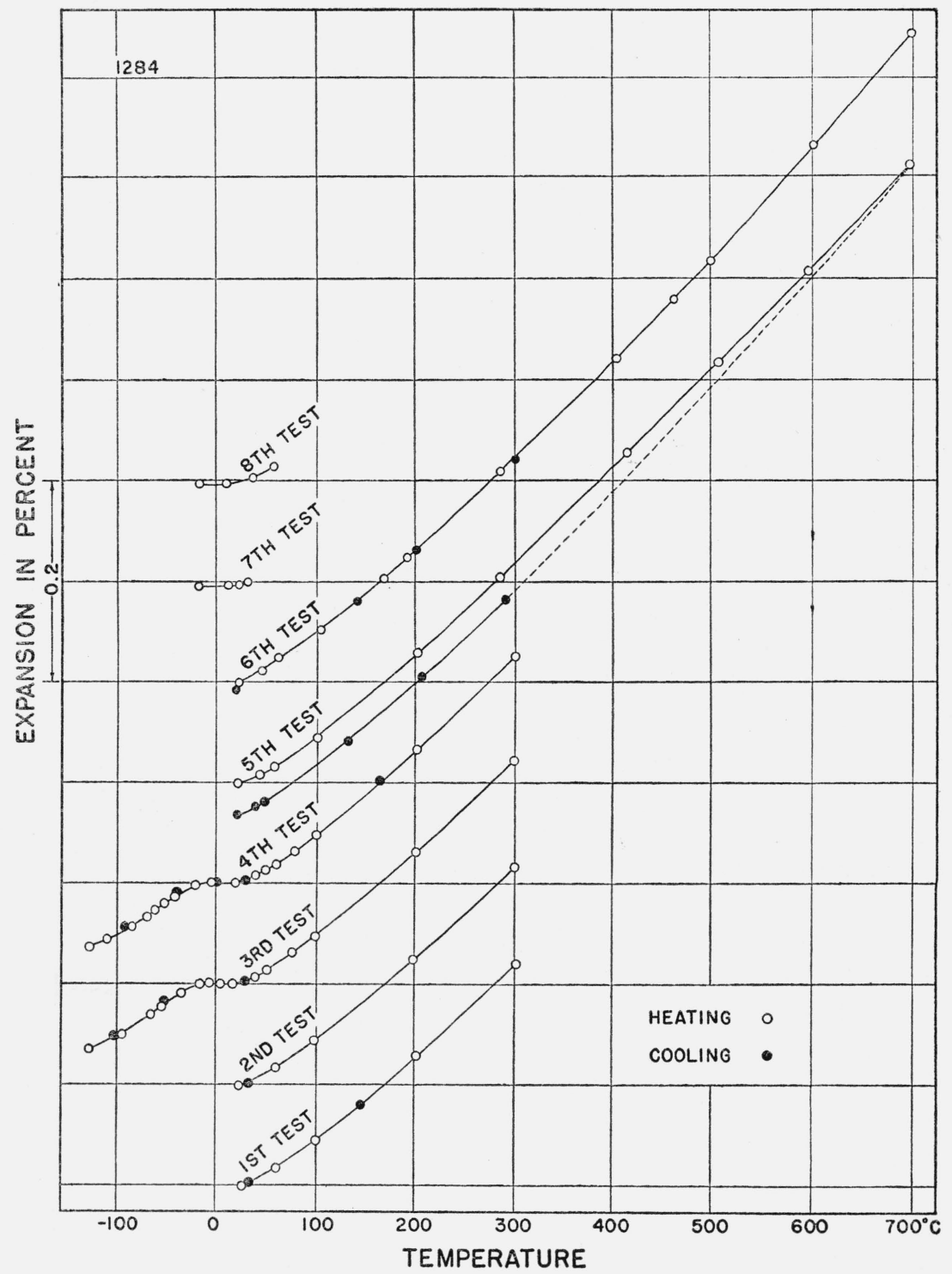

FIGURE 2.-Linear thermal expansion of hot-swaged chromium, 98.3 percent.

Figure 2 shows the observations in eight tests on the hot-swaged 98.3-percent chromium (sample 1284). In tests 1 to 4 between $-127^{\circ}$ and $+303^{\circ} \mathrm{C}$ the solid circles representing the observations on cooling nearly coincide with the expansion curves. In the fifth test to $700^{\circ} \mathrm{C}$ the curve on cooling lies appreciably below the curve 
obtained on heating. The observations on cooling in the sixth test over the same temperature range lie slightly below the expansion curve. The curves of tests $3,4,7$, and 8 indicate anomalous expansion between $-20^{\circ}$ and $+20^{\circ} \mathrm{C}$. In this region the curves are nearly horizontal.

The observations obtained in three tests on cooling the cast 97.4percent chromium (sample 1443I) are shown in figure 3 . The curves indicate that this sample expands slightly on cooling between $0^{\circ}$ and $-20^{\circ} \mathrm{C}$. The lower and the upper portions of the curves in the first test are practically straight. The curves in tests 2 and 3 are slightly concave toward the temperature axis.

The observations obtained in a total of six tests on two samples of hot-swaged 96.7-per-

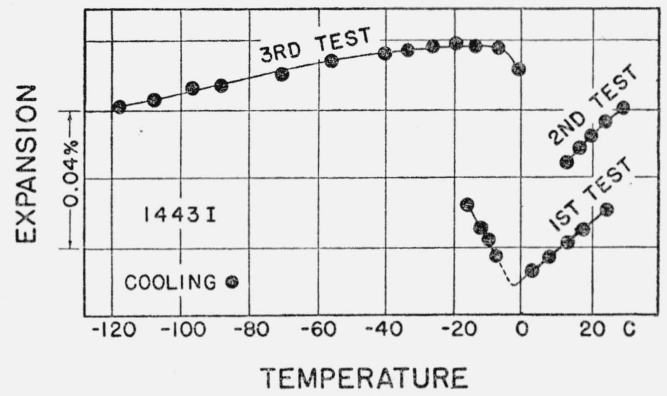

FIGURE 3.-Linear thermal expansion of cast chromium, 97.4 percent.

cent chromium (samples 1356 and 1356I) at various temperatures between $-190^{\circ}$ and $+702^{\circ} \mathrm{C}$ are shown in figures 4 and 5 . A slight irregularity was noted near $0^{\circ} \mathrm{C}$.

Figure 6 shows the observations in six tests on the cast 96.3-percent chromium (sample 1285). In tests 1 to 4 between $-124^{\circ}$ and $+301^{\circ}$ $\mathrm{C}$, the solid circles representing the observations on cooling nearly

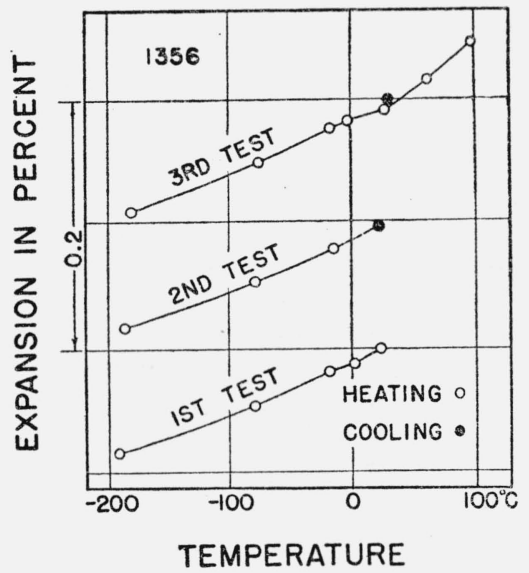

FIGURE 4.-Linear thermal expansion of hot-swaged chromium, 96.7 percent. coincide with the expansion curves obtained on heating. In tests 3 and 4 on cooling from about $-30^{\circ}$ to $-50^{\circ} \mathrm{C}$ there was an expansion which was reversible on heating through the same temperature range. Below $-50^{\circ} \mathrm{C}$ the curves are slightly concave toward the temperature axis. In the fifth test to $700^{\circ} \mathrm{C}$ the contraction curve lies appreciably below the expansion curve. In the sixth test to $700^{\circ} \mathrm{C}$ the observations on cooling lie slightly below the expansion curve.

Average coefficients of expansion computed for various temperature ranges from the expansion and contraction curves are given in table 2. The last column of the table shows the difference in length before and after each expansion test indicated. The coefficients of expansion of sampels 1284, 1443I, and 1285 are exceptionally low in or near the regions where anomalous expansion was observed. In these regions the coefficients are, in some instances, negative. 


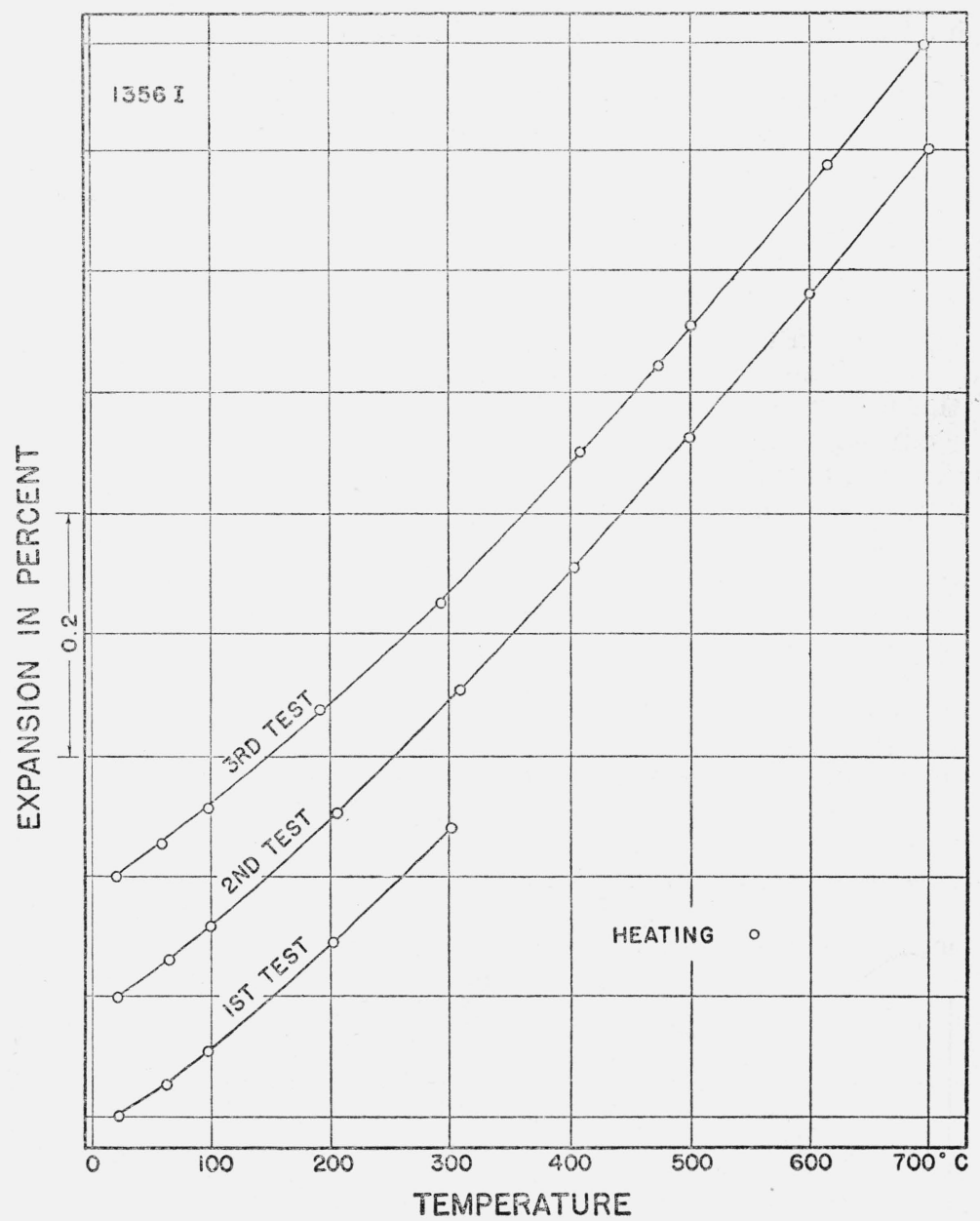

Figure 5.-Linear thermal expansion of hot-swaged chromium, 96.7 percent.

Table 3 gives a comparison of the average coefficients of expansion of the samples of cast and of swaged chromium in the present investigation with the average coefficients of expansion of electrolytic chromium obtained by the author [1] in a previous investigation. The average coefficients of expansion of electrolytic chromium for various temperature intervals between $20^{\circ}$ and $700^{\circ} \mathrm{C}$ are within the ranges of the coefficients of expansion for the samples of cast and of swaged chromium. 


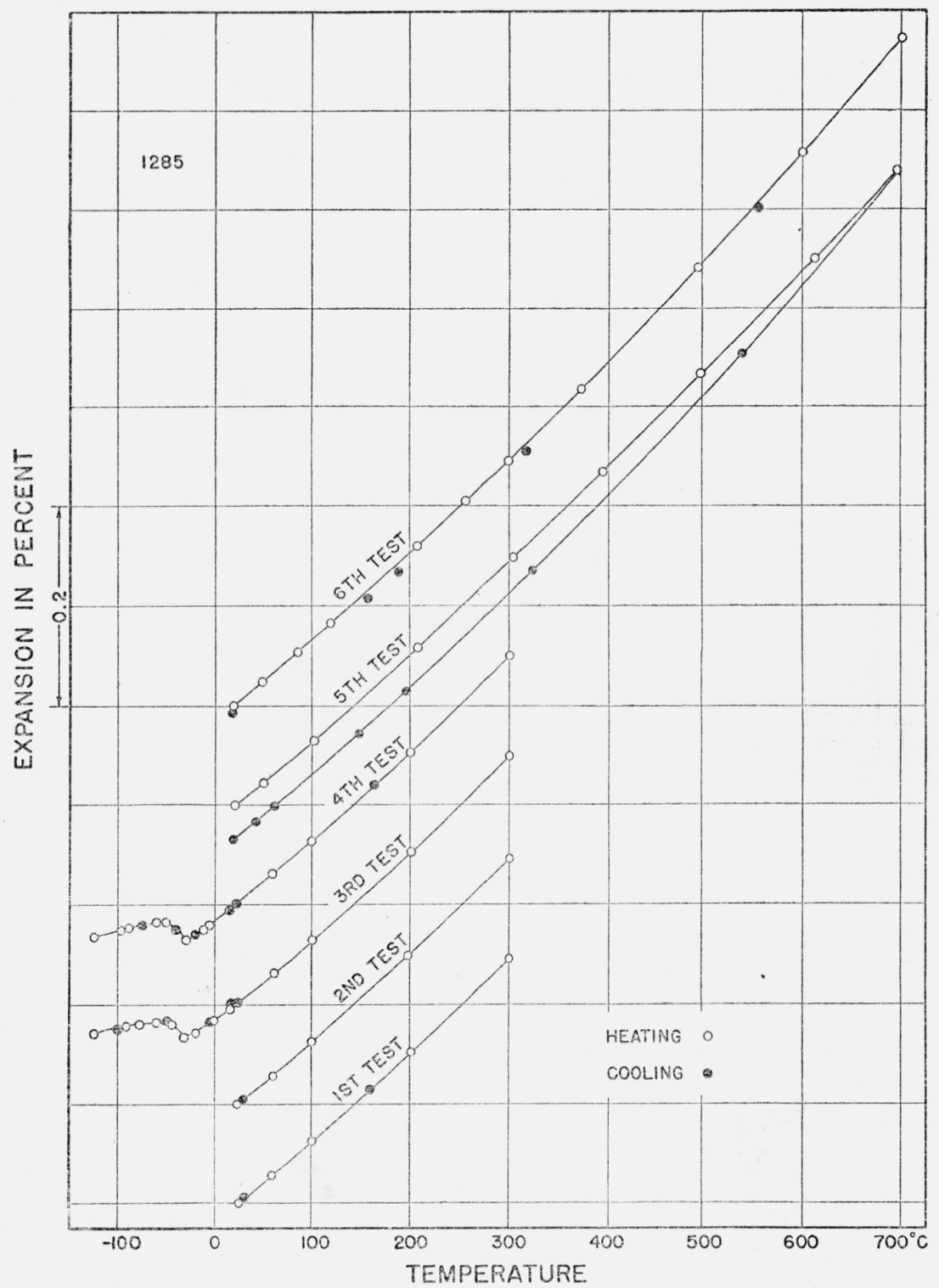

FiguRE 6.-Linear thermal expansion of cast chromium, 96.3 percent. 
TABLE 2.-Coefficients of linear expansion of chromium

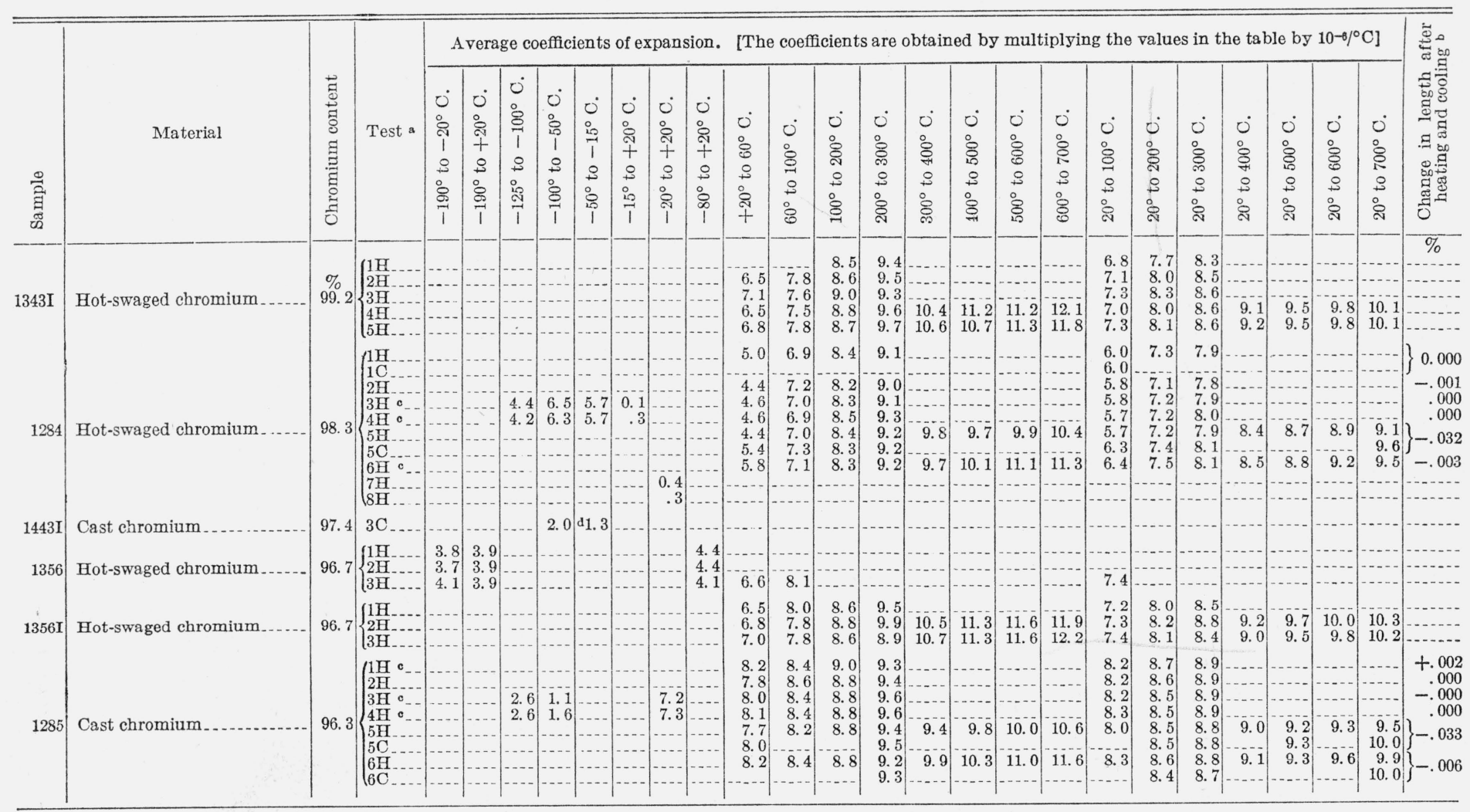

a H indicates heating, and C, cooling.

curve on heating and the contraction curve (or obserindicates an increase in length and the minus sign a decrease in length. - Observations on cooling close to expansion curve on heating.
d From $-50^{\circ}$ to $-20^{\circ} \mathrm{C}$. 
TABLE 3.-Comparison of coefficients of expansion of chromium

\begin{tabular}{|c|c|c|}
\hline \multirow[b]{2}{*}{ Temperature range } & \multicolumn{2}{|c|}{$\begin{array}{l}\text { Average coefficients of } \\
\text { expansion }\end{array}$} \\
\hline & $\begin{array}{l}\text { Samples of cast } \\
\text { and of swaged } \\
\text { chromium ( } 99.2 \\
\text { to } 96.3 \text { percent) }\end{array}$ & $\begin{array}{c}\text { Electrolytic } \\
\text { chromium s } \\
\text { (99.3 and } \\
98.7 \text { percent) }\end{array}$ \\
\hline $\begin{array}{l}{ }^{\circ} C \\
20 \text { to } 100 \\
20 \text { to } 200 \\
20 \text { to } 300 \\
20 \text { to } 400 \\
20 \text { to } 500 \\
20 \text { to } 600 \\
20 \text { to } 700\end{array}$ & $\begin{array}{l}\times 10^{-6} /{ }^{\circ} C \\
5.7 \text { to } 8.3 \\
7.1 \text { to } 8.7 \\
7.8 \text { to } 8.9 \\
8.4 \text { to } 9.2 \\
8.7 \text { to } 9.7 \\
8.9 \text { to } 10.0 \\
9.1 \text { to } 10.3\end{array}$ & $\begin{array}{r}\times 10^{-6} /{ }^{\circ} \mathrm{C} \\
6.8 \\
7.4 \\
8.0 \\
8.5 \\
8.9 \\
9.2 \\
9.5\end{array}$ \\
\hline
\end{tabular}

a Computed from Hidnert's [1] eq 2.

Figure 7 shows the coefficients or rates of expansion, defined as $\left(1 / L_{20}\right)(d L / d t)$, at various temperatures between $40^{\circ}$ and $650^{\circ} \mathrm{C}$. The length of a specimen at temperature $t$ is represented by $L$ and its length at $20^{\circ} \mathrm{C}$ by $L_{20}$. The coefficients were derived from the average coefficients of expansion in table 2 . Each vertical line at the

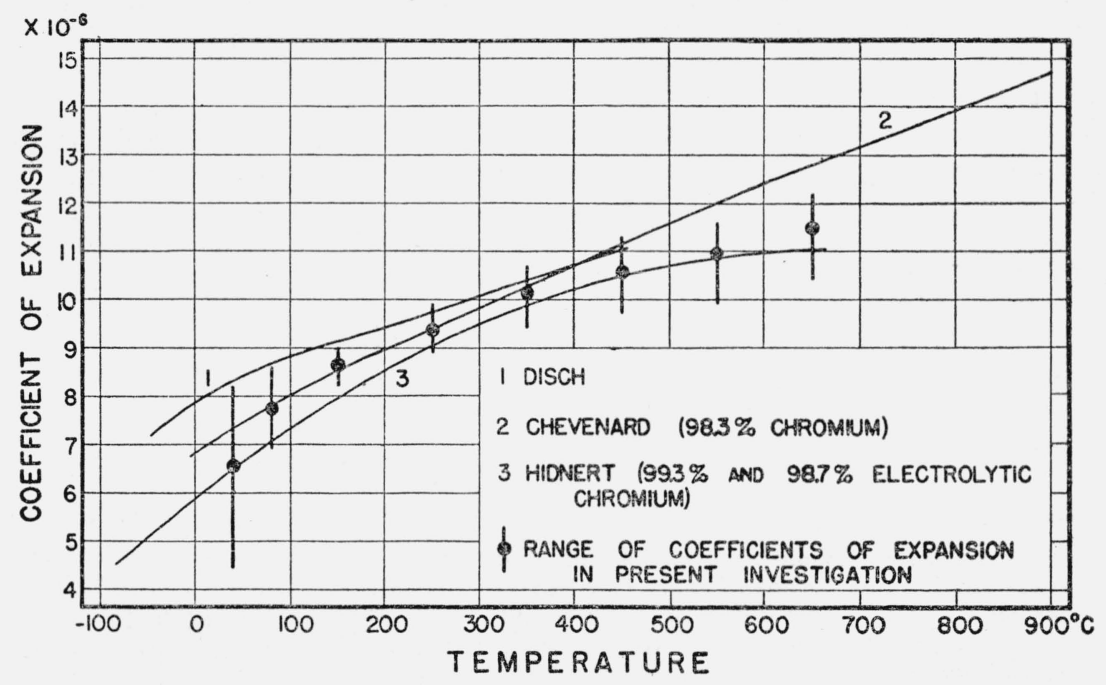

FIGURE 7.-Comparison of coefficients of expansion $\left(\right.$ per $\left.{ }^{\circ} \mathrm{C}\right)$ obtained in the present investigation on cast and on swaged chromium (99.2 to 96.3 percent) and in previous investigations by Disch [6], Chevenard [7], and Hidnert [1].

temperatures indicated represents the range of the coefficients of expansion of the samples of chromium. The circle on each vertical line indicates the average of the coefficients of expansion at that temperature. This figure includes a curve derived from the data by Disch [6] on a sample of unknown purity, a curve from Chevenard [7] on a sample of chromium containing 98.3 percent chromium, ${ }^{4}$ and a curve

\footnotetext{
4 Impurities principally aluminum and iron, but amounts were not indicated by Chevenard.
} 
from Hidnert [1] on two samples of electrolytic chromium (99.3 and 98.7 percent). A curve drawn through the circles representing the averages of the coefficients of expansion obtained in the present investigation at various temperatures from $40^{\circ}$ to $650^{\circ} \mathrm{C}$ lies close to

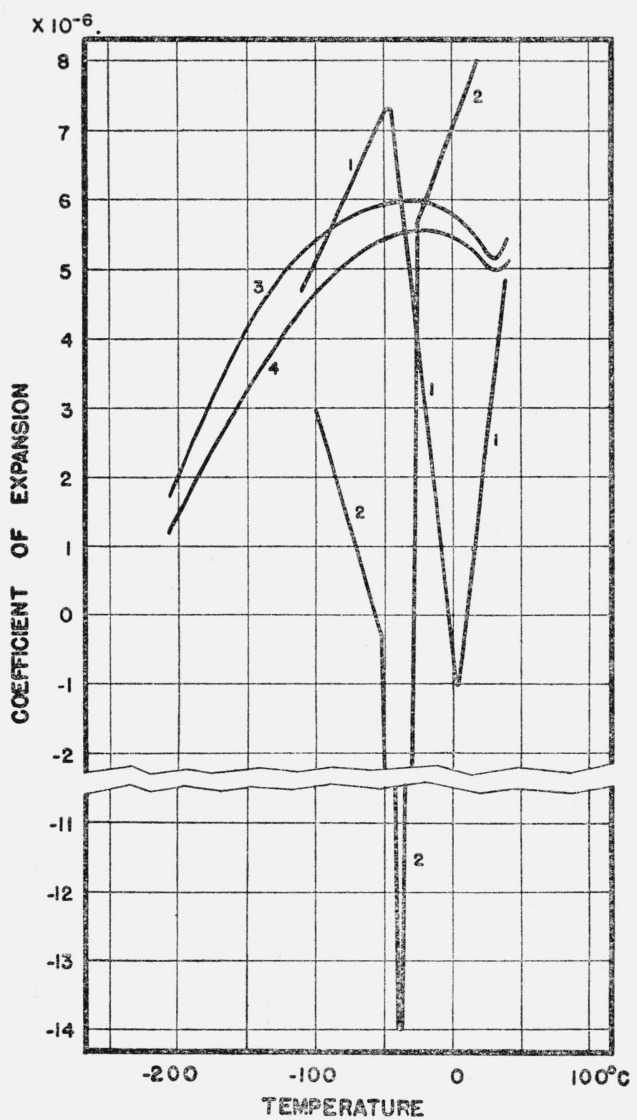

Figure 8.-Comparison of coefficients of expansion (per ${ }^{\circ} C$ ) and anomalies in expansion of chromium obtained in the present investigation at low temperatures and in a recent investigation by Erfling [8].

Curve 1.-Sample 1284, hot-swaged chromium (98.3 percent). Curve 2.-Sample 1285, cast chromium (96.3 percent).

Curves 3 and 4 by Erfling [8] on sheet-rolled chromium and electrolytic chromium, respectively. further cooling. The contraction between $+20^{\circ}$ and $-183^{\circ} \mathrm{C}$ was $1.25 \mathrm{~mm} / \mathrm{m}$, and that between $+20^{\circ}$ and $-190^{\circ} \mathrm{C}$ was $1.0 \mathrm{~mm} / \mathrm{m}$. He was unable to obtain accurate values because the surfaces of the sample deformed at low temperatures.

The present investigation shows that the expansion anomaly in chromium is spread over a range of temperature and is not abrupt as in the polymorphic transition, or phase change, of iron at about $910^{\circ}$ C. The anomaly is reversible on heating and cooling, without

\footnotetext{
${ }^{5}$ Derived from the original observations in the third and the fourth tests on heating and on cooling.
} 
hysteresis. Bridgman [9] pointed out that phase changes in impure substances are spread over a range of temperature instead of being abrupt, but that phase changes in the presence of impurity are accompanied by hysteresis effects on account of the diffusion of the impurity from one phase to the other. As chromium does not show hysteresis, it appears that the anomaly does not represent a phase change.

Erfling [8] found that the rate of expansion decreased slightly from about $-30^{\circ}$ to $+30^{\circ} \mathrm{C}$ for sheet-rolled chromium and from about $-10^{\circ}$ to $+30^{\circ} \mathrm{C}$ for electrolytic chromium. Larger decreases in the rates of expansion were noted in the present investigation on two samples of chromium (see fig. 8). The rate of expansion of the sample of hot-swaged chromium (98.3 percent) decreased from about $-50^{\circ}$ to $0^{\circ} \mathrm{C}$. The curve for the sample of cast chromium (96.3 percent) indicates that the rate of expansion decreased from $-100^{\circ}$ to about $-30^{\circ} \mathrm{C}$.

Anomalous effects in other properties of chromium have been observed by Bridgman [9] and Söchtig [10]. Bridgman's curve for the relative electrical resistance of a swaged rod of chromium plotted as a function of temperature shows an anomaly at about $10^{\circ} \mathrm{C}$. $\mathrm{He}$ found no hysteresis between resistance and temperature $\left(-80^{\circ}\right.$ to $+80^{\circ} \mathrm{C}$ ). He concluded that for those substances which do not show hysteresis, the mechanism responsible for the anomaly may be some intimate affair of the structure elements, and cannot be anything like those changes of lattice type that involve tearing down and building up again the lattice structure with comparatively large motions of some of the elements of the lattice or like anything else that involves motion of the elements of the structure through large distances.

Söchtig [10] investigated the electrical resistance of three samples of chromium. His curves show anomalies at about $40^{\circ} \mathrm{C}$ for electrolytic chromium and sheet-rolled chromium, and at $-3^{\circ} \mathrm{C}$ for chromium of lower purity. ${ }^{6}$ He also found no hysteresis in the electrical resistance with increasing and decreasing temperatures. In the temperature range of the anomaly, Söchtig found no change in the magnetic properties or in the structure of chromium. He concluded that the anomalous behavior of chromium cannot be ascribed to a change in the lattice structure but to the changes in the elastic forces between the atoms and the movement or attraction of the electrons.

Sasaki and Sekito [11] reported three crystalline forms of electrolytic chromium. They found that the hexagonal form is transformed at room temperature into the body-centered cubic form after 40 days from deposition, and that the form of the $\alpha-\mathrm{Mn}$ type is also transformed into the body-centered cubic form after about 230 days. Wood [12] found that on heating the hexagonal structure of electrodeposited chromium a transition to the cubic form began at about $100^{\circ} \mathrm{C}$ and was complete at about $130^{\circ} \mathrm{C}$.

The lack of hysteresis reported by Bridgman [9] and Söchtig [10] is confirmed by results of the present investigation between $-190^{\circ}$ and $+300^{\circ} \mathrm{C}$. Figures 2 and 6 show that the samples of chromium indicate hysteresis on heating to $700^{\circ} \mathrm{C}$ and cooling to room temperature.

3 Purity of 3 samples of chromium not indicated by söchtig. 
As previous investigators failed to indicate the purity of the chromium samples on which anomalies were observed, it is not possible to correlate these anomalies with the composition. The results of the present investigation appear to indicate that the temperature at which anomalous expansion occurs decreases with decrease in the purity of the chromium.

Table 1 shows that the densities of the samples of chromium of the present investigation lie between 6.86 and $7.14 \mathrm{~g} / \mathrm{cm}^{3}$. From the lattice constants for the hexagonal form, the body-centered cubic form and the cubic form of the $\alpha$-Mn type, Sasaki and Sekito [11] calculated the densities $6.08,7.21$, and 7.48 , respectively. The observed densities are in closest agreement with the calculated density for the cubic form of chromium.

In view of the fact that chromium of various purities indicates anomalies at low temperatures, it appears that investigation of the properties of various chromium alloys at low temperatures may disclose other anomalous effects.

The author expresses his appreciation to the companies indicated in section II of this paper for the samples of chromium.

\section{REFERENCES}

[1] P. Hidnert, Thermal expansion of electrolytic chromium, J. Research NBS 26, 81 (1941) RP1361.

[2] G. E. Merritt, The interference method of measuring thermal expansion, BS J. Research 10, 59 (1933) RP515.

[3] J. B. Saunders, Improved interferometric procedure with application to expansion measurements, J. Research NBS 23, 179 (1939) RP1227.

[4] W. Souder and P. Hidnert, Measurements on the thermal expansion of fused silica, Sci. Pap. BS 21, 1 (1926) S524.

[5] P. Hidnert and W. T. Sweeney, Thermal expansion of magnesium and some of its alloys, BS J. Research 1, 771 (1928) RP29.

[6] J. Disch, Über die Wärmeausdehnung einiger Stoffe, Z. Physik 5, 173 (1921); Wiss. Abh. physik.-tech. Reichanstalt 5, 263 (1921).

[7] P. Chevenard, Dilatabilité du chrome et des alliages nickel-chrome dans un intervalle étendu de températures, Comptes rend. 174, 109 (1922).

[8] H. D. Erfling, Studien zur thermischen Ausdehnung fester Stoffe in tiefer Temperatur, Ann. Physik 34, [5] 136 (1939).

[9] P. W. Bridgman, Compressibilities and pressure coefficients of resistance of elements, compounds, and alloys, many of them anomalous, Proc. Am. Acad. Arts Sci. 68, 27 (1932-33).

[10] H. Söchtig, Untersuchungen an reinem Chrom im Anomaliegebiet, Ann. Physik 38, [5] 97 (1940).

[11] K. Sasaki and S. Sekito, Three crystalline modifications of electrolytic chromium, J. Soc. Chem. Ind. Japan 33, 482B (1930).

[12] W. A. Wood, Transition from hexagonal to cubic electrodeposited chromium, Phil. Mag. 24 [7], 511 (1937).

Washington, April 8, 1941. 